A diagnosis of obliterative pulmonary hypertension of unknown cause, presumed thrombo-embolic, possibly secondary to vasoconstriction, was made, and she was started on phenindione. She returned to Egypt and has not been seen since.

Comment.-The physical signs were most unusual in this patient, the loud ejection murmur and soft pulmonary closure being unexplained. A long, loud systolic murmur arising from the pulmonary artery is exceptional in severe pulmonary hypertension with low cardiac output. However, the delay in pulmonary closure may have been due to a partial defect of conduc- tion in the right bundle branch resulting from right ventricular enlargement, and the pansystolic murmur to tricuspid insufficiency. The history of symptoms from an early age suggests that the condition may have started as "idiopathic" pulmonary hypertension but was succeeded by thrombosis or embolic occlusion. In either event, anticoagulant treatment seemed to offer the only hope of relief.

[The second half of this paper, together with a list of references, will appear in our next issue.]

\title{
RUBELLA EMBRYOPATHY
}

\section{AN INTERIM REPORT ON A NEW ZEALAND EPIDEMIC}

BY

\section{G. C. LIGGINS, M.B., F.R.A.C.S., F.R.C.S.Ed. M.R.C.o.G. \\ L. I. PHILLIPS, M.B., M.R.C.P., D.C.H. \\ Postgraduate School of Obstetrics and Gynaecology, University of Auckland, and the National Women's Hospital, Auckland, New Zealand}

It is firmly established that maternal rubella is a cause of embryopathy and that the risk varies inversely with the duration of pregnancy. However, the likelihood of foetal malformation in a particular pregnancy complicated by rubella remains a matter of speculation, since the incidence has differed widely in reported prospective surveys. The occurrence of an unusually extensive rubella epidemic in 1959 presented an opportunity to determine statistics in New Zealand.

\section{Material and Methods}

The time-course of the epidemic is indicated in the Chart which is constructed from the returns of a group of 10 general practitioners who voluntarily notify certain infectious diseases not usually notifiable. General practitioners and obstetricians in the Auckland city area were asked to notify all cases of maternal

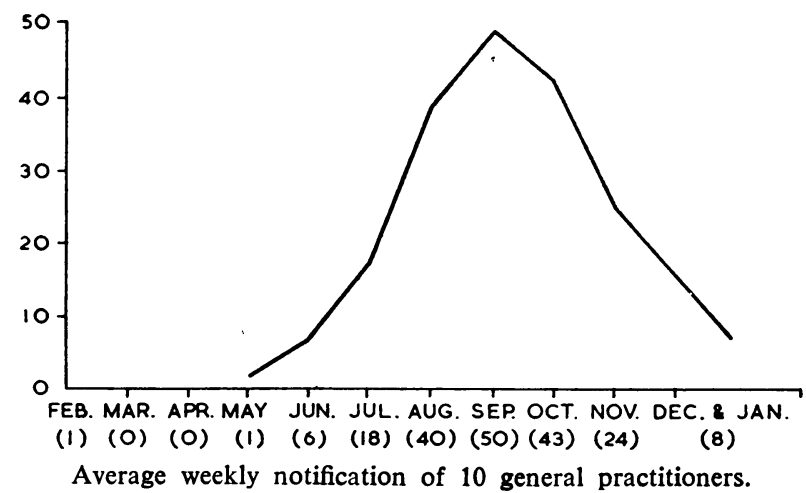

rubella irrespective of the period of gestation. Those cases fulfilling the following criteria were included in the survey: (1) the rash was seen and diagnosed as rubella by a doctor. (2) pregnancy was progressing normally at the time of notification, and (3) the date of the last menstrual period and the appearance of the rash were known accurately.

There were 89 acceptable cases. Therapeutic abortion was performed in 15 and spontaneous abortion ended a further seven pregnancies, leaving 67 viable pregnancies for study.
Babies were examined soon after delivery by a paediatrician wherever possible. Subsequently each child was examined after the age of 6 months by a paediatrician, an ophthalmologist, an audiometrist, and in some cases by a paediatric cardiologist. Further follow-up visits were arranged at intervals until the presence of a major malformation could be excluded. The ages of the children at the last examination ranged from 10 to 24 months.

\section{Results}

Three infants died. The youngest of these was aged 28 hours, and post-mortem examination revealed atelectasis and a patent ductus arteriosus. This is not included as a rubella malformation. The second death occurred at 5 weeks from cardiac failure in a baby with patent ductus arteriosus, atrial septal defect, and bilateral cataracts. The third death occurred at 15 months from pneumonia in an infant with bilateral cataracts, gross mental retardation, brachycephaly, and probable deafness.

Table I gives details of the 12 cases with abnormalities attributed to rubella. This includes the two deaths previously mentioned. Although only one was born prematurely by gestation the average birth weight of these babies was only $5 \frac{3}{4} \mathrm{lb}$. $(2,610 \mathrm{~g}$.). In all cases with rubella embryopathy, rubella had occurred in the first 15 weeks of pregnancy. Eight of the 12 cases had multiple abnormalities. In all of these babies maternal rubella had occurred within the first eight weeks of pregnancy. Two additional babies had functional murmurs-one was identified as a venous hum (rubella at 16 weeks) and the other murmur disappeared within 12 months (rubella at 22 weeks). The only abnormality found after 15 weeks was the absence of one pinna in a baby whose mother had rubella at 39 weeks' gestation.

Table II lists the frequency of the various types of rubella abnormality. There were nine infants with eye defects, including four with bilateral cataracts, two with unilateral cataracts (one of these with glascoma in the opposite eye), and three with pigmentation of the retina; one of the latter also had a unilateral cataract. All the babies with cataracts had needling operations at various times during the first year of life. Eight infants had 
bearing defects, all with bilateral perceptive deafness, mostly severe; the majority of these wear hearing-aids and are having follow-up examinations at intervals. Seven infants had heart defects of which patent ductus arteriosus was the most common (four cases). One baby died aged 5 weeks in cardiac failure, having an atrial septal defect in addition to the patent ductus. In the second case the ductus was ligated at eight weeks, the third at five months, and the fourth closed spontaneously at four months. Two have probable aortic stenoses and one probably has a coarctation of the pulmonary arteries.

Mental retardation was found in only one case. This was of marked degree, was associated with brachycephaly and bilateral cataracts, and resulted in death from pneumonia at 15 months.

Table III gives the incidence of babies with rubella embryopathy due to rubella at varying stages in pregnancy. The incidence was $100 \%$ in the first four weeks, $50 \%$ in the 5 th to 8 th weeks, $13 \%$ in the 9 th to 12 th weeks, and $12 \%$ in the 13 th to 16 th weeks.

TaBle I.-Rubella Abnormalities in Relation to Gestation

\begin{tabular}{|c|c|c|c|c|c|c|}
\hline \multirow{2}{*}{$\begin{array}{l}\text { Case } \\
\text { No. }\end{array}$} & \multirow{2}{*}{$\begin{array}{c}\text { Gesta- } \\
\text { tional } \\
\text { Week } \\
\text { at } \\
\text { Delivery }\end{array}$} & \multicolumn{2}{|c|}{$\underset{\text { Weight }}{\text { Birth }}$} & \multirow{2}{*}{$\begin{array}{l}\text { Age at } \\
\text { Last } \\
\text { Examina- } \\
\text { tion } \\
\text { (Months) }\end{array}$} & \multirow{2}{*}{$\begin{array}{l}\text { L.M.P.- } \\
\text { App. } \\
\text { of } \\
\text { Rash } \\
\text { (Days) }\end{array}$} & \multirow{2}{*}{ Abnormalities } \\
\hline & & 1b. or & g. & & & \\
\hline 1 & 40 & 64 & 2,835 & 12 & 21 & C.H.D. P.D.A. Pig- \\
\hline 2 & 37 & 58 & 2,495 & 24 & 28 & $\begin{array}{l}\text { C.H.D. Aortic steno- } \\
\text { sis. Cataracts. }\end{array}$ \\
\hline 3 & 41 & 412 & 2,155 & 15 & 30 & $\begin{array}{l}\text { C.H.D. A.S.D. } \\
\text { P.D.A. Cataracts. } \\
\text { Died } 5 \text { weeks. }\end{array}$ \\
\hline 4 & 40 & 66 & 2,890 & 15 & 39 & $\begin{array}{l}\text { C.H.D. Aortic steno- } \\
\text { sis. Left cataract, } \\
\text { pigmentation right } \\
\text { fundus. Deafness }\end{array}$ \\
\hline 5 & 40 & 312 & 1,700 & 14 & 39 & $\begin{array}{l}\text { C.H.D. P.D.A. Right } \\
\text { cataract. Left } \\
\text { glaucoma. Deafness }\end{array}$ \\
\hline 6 & 40 & 43 & 1,900 & 14 & 40 & $\begin{array}{l}\text { C.H.D. Coarctation } \\
\text { pulmonary arteries. } \\
\text { Pigmentation fundi }\end{array}$ \\
\hline 7 & & 71 & 3,205 & 10 & 46 & $\begin{array}{l}\text { Cataracts. Deafness. } \\
\text { Mental retardation. } \\
\text { Brachycephaly. } \\
\text { Died 15 months }\end{array}$ \\
\hline 8 & 40 & 59 & 2,525 & 16 & 49 & C.H.D. P.D.A. \\
\hline $\begin{array}{r}9 \\
10 \\
11 \\
12\end{array}$ & $\begin{array}{l}41 \\
39 \\
43 \\
40\end{array}$ & $\begin{array}{rr}5 & 6 \\
6 & 2 \\
6 & 7 \\
7 & 12\end{array}$ & $\begin{array}{l}2,440 \\
2,780 \\
2,920 \\
3,530\end{array}$ & $\begin{array}{l}16 \\
11 \\
24 \\
13\end{array}$ & $\begin{array}{r}77 \\
84 \\
88 \\
105\end{array}$ & $\begin{array}{l}\text { Deafness } \\
\text { Pigmentation fundi } \\
\text { Deafness } \\
\quad, "\end{array}$ \\
\hline
\end{tabular}

C.H.D. $=$ Congenital heart disease. A.S.D $=$ Atrial septal defect. Y.C.H.F. $=$ Congestive heart failure. P.D.A. $=$ Patent ductus arteriosus.

TABLE II.-Frequency of Types of Rubella Abnormality

\begin{tabular}{|c|c|c|c|}
\hline \multicolumn{2}{|c|}{ Abnormality } & $\begin{array}{c}\text { No. of Babies } \\
\text { with }\end{array}$ & Type \\
\hline Eye] & $\ldots$ & 9 & $\begin{array}{l}4 \text { bilateral cataracts. } 2 \text { unilateral } \\
\text { cataracts ( } 1 \text { with glaucoma also). } \\
3 \text { pigmentation of retina }\end{array}$ \\
\hline Hearing & $\cdots$ & 8 & All bilateral perceptive deafness, \\
\hline $\begin{array}{l}\text { Heart } \\
\text { Mental r }\end{array}$ & tardation & 7 & $\begin{array}{l}4 \text { patent ductus (1 with A.S.D. also). } \\
2 \text { aortic stenosis. } 1 \text { coarctation } \\
\text { pulmonary arteries } \\
\text { Severe }\end{array}$ \\
\hline
\end{tabular}

TABle III.-Incidence of Abnormalities in Each Period of

\begin{tabular}{c|c|c|c} 
& \multicolumn{3}{|c}{ Gestation } \\
\hline $\begin{array}{c}\text { Gestation } \\
\text { Weeks of }\end{array}$ & Total No. & \multicolumn{2}{|c}{ Abnormal } \\
\cline { 2 - 3 } Rubella & & No. & $\%$ \\
\hline $1-4$ & 2 & 2 & 100 \\
$5-8$ & 12 & 6 & 50 \\
$9-12$ & 15 & 2 & 13 \\
$13-16$ & 16 & 2 & 12 \\
$1-13$ & 32 & 11 & 34 \\
\hline
\end{tabular}

Multiple defects, of which there were eight, all occurred in the first eight weeks of pregnancy and single defects, of which there were four, all occurred between 11 and 15 weeks. Thirty-four per cent of babies were born with abnormalities where maternal rubella occurred in the first 12 weeks, and the same figure applies to the first trimester.

Table IV lists the cases in which pregnancy was terminated. In all cases rubella appeared within the first 12 weeks of pregnancy. Twelve of the 15 come into the group of high foetal risk, rubella occurring in the first eight weeks of pregnancy.

TABle IV.-Termination of Pregnancy for Rubella (1959-60)

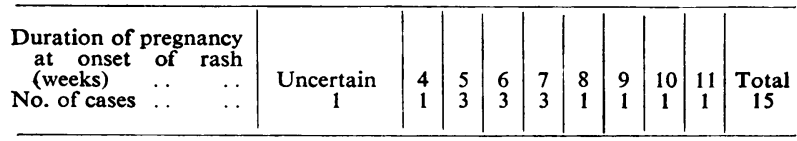

\section{Discussion}

Accurate statistics of the epidemiology of rubella in New Zealand are not available as it is not a notifiable disease. No previous prospective survey of malformation rates in this country has been made, but a study of epidemic deafness was published by Lancaster and Pickering (1952). They showed that there were certain years of peak incidence of births of deaf children in New Zealand. The first of these was in 1899, when 29 deaf children were born compared with 8 in 1898 and 16 in 1900 . An extensive epidemic of rubella was known to have occurred in both Australia and New Zealand in 1898. No further peak of epidemic deafness occurred until 1939, in which year 126 deaf children were born compared with 28 in 1938 and 22 in 1940 . This followed a rubella epidemic in Australia in 1938, beginning about five months later in New Zealand.

Pitt (1961) showed epidemic peaks of rubella in Australia late in 1956, 1957, and 1958, the latter being the biggest. This was followed in 1959 by a rubella epidemic in New Zealand similar to that of 1939, which also followed an earlier Australian epidemic.

Further follow-up examination is planned for each child at about 4 years of age. This may increase the incidence of deafness following rubella during the first 16 weeks of pregnancy $(17.7 \%)$. Jackson and Fisch (1958), who found an incidence of $16.8 \%$, emphasized the need for late follow-up to diagnose mild and unilateral deafness.

Of interest is a case of probable coarctation of the pulmonary arteries which R. D. Rowe (personal communication, 1962) has found to occur sufficiently often after maternal rubella to be a characteristic rubella embryopathy.

\section{Summary}

An unusually extensive epidemic of rubella which occurred in New Zealand in 1959 provided the material for a prospective survey of foetal abnormality arising from maternal rubella.

A total of 89 cases were admitted to the series. This was reduced by 15 therapeutic abortions and 7 spontaneous abortions, leaving 67 viable pregnancies for study.

Of the 32 pregnancies in which the rash appeared during the first trimester, foetal abnormality was found in $11(34 \%)$. One further case of foetal abnormality followed rubella at the 15 th week of pregnancy. 
Rubella appearing after the 49th day was not associated with multiple abnormalities.

The co-operation of the general practitioners and obstetricians of Auckland made this study possible and we are most grateful to them. Our thanks are also due to Dr. J. D. Matthews (paediatrician), Mr. C. Swanston (ophthalmologist), Dr. R. D. Rowe (paediatric cardiologist), Dr. D. M. O. Becroft (pathologist), Dr. B. Christmas (M.O.H.), and Mr. J. D. deVere (audiometrist) for considerable time and effort. Mrs. B. Duckmanton gave untiring clerical assistance.

\section{REFERENCES}

Jackson, A. D. M., and Fisch, L. (1958). Lancet, 2, 1241. Lancaster, H. O., and Pickering, H. (1952). N.Z. med. J., 51 184

Pitt, D. B. (1961). Med. J. Aust., 48, 881.

\section{PLACE OF THE hOSPITAL IN THE CARE OF THE MENTALLY SUBNORMAL}

BY

JOYCE LEESON, M.B., Ch.B., D.P.H.

Assistant Lecturer, Social and Preventive Medicine, University of Manchester

The number of patients in hospitals for the mentally subnormal has increased recently and the waiting-lists for admission to these hospitals remain long-and this at a time of growing optimism about maintaining subnormal individuals outside the large hospitals as useful members of the community (Clarke and Clarke, 1958). This optimism was derived from studies of their social and industrial potentials. Tizard (1960) reported on the progress of young medium-grade subnormal children who were cared for in small groups which tried to provide a substitute family environment. He found that they developed their social and verbal abilities more rapidly than a comparable group of children who remained in a large ward of a mental deficiency hospital. O'Connor and Tizard (1956) studied the learning abilities of adult imbeciles and found that some of them could attain the standards necessary for employment in open industry, and that others could become selfsupporting in sheltered workshops. Many such patients can live at home or in hostels, and travel to work each day (Susser and Kushlick, 1961).

Stein and Susser (1960a) thought that social and psychiatric support in the community might enable many high-grade subnormal patients who would otherwise be admitted to hospital to remain outside until they reached maturity and could fend for themselves.

Yet the demand for hospital admission persists. Family studies have suggested some of the reasons why this may be so for the severely subnormal (Grad, 1958; Leeson, 1960). Great strains, physical and psychological, fall upon a family with a mentally subnormal member, and up to now the community services have not provided enough support to enable families to withstand the strain. The local and national reports of the mental health services reveal that the lack of facilities is even more marked when the needs of the high-grade subnormals are considered.

Thus although the advantages of community care for subnormal patients are often stressed, the hospitals have been faced with a heavy demand for their accommodation.
The consequent shortage of vacant beds caused the Manchester Regional Hospital Board to finance an investigation into the demand for hospital care for the subnormal, some of the findings of which are presented here.

\section{Methods}

The data are taken from the records held by the Regional Hospital Board Bed Bureau and by the hospitals in the region. These records were compiled by many different persons for administrative purposes and not for research. It is likely, therefore, that they contain individual inaccuracies and errors in recording, but there is no reason to believe that there is any consistent bias which would distort the findings. On the aspects discussed in this paper, information was available on almost every case.

Four groups of patients have been studied. (1) The 682 patients who were on the waiting-list for admission to hospital in December, 1958. These represented the problem of demand as the Regional Hospital Board saw it. (2) The 973 patients who were admitted to a mental deficiency hospital during 1954-8. In order to get a more detailed picture of the circumstances which caused the admission of these patients, the records of the admissions of two years-that is, 1956 and 1957-were examined closely in an attempt to elucidate the factors involved. (3) The 1,309 patients who made up a $20 \%$ random sample of all the mental deficiency hospital inpatients in the region at the end of 1959. (4) The 243 patients who left the hospitals in the years 1954-8. These were a $20 \%$ random sample of all hospital leavers, excluding transfers and those remaining on licence.

\section{Patients on the Waiting-list}

Table I shows the age and sex distribution for the three grades of patients on the waiting-list in December, 1958. High, medium, and low grades correspond roughly to the categories feeble-minded, imbecile, and idiot respectively. (Under the 1959 Mental Health Act the feeble-minded are described as subnormal and the last two categories grouped together as severely subnormal.) It can be seen that there were few high-grade patients on the waiting-list and that these were mostly adults. There were more females than males. Half of the medium-grade patients were under 20 years, while the largest single age-group was that of low-grade children aged 5-9 years. Among the severely subnormal, males outnumbered females by nearly 3 to 2 .

One-third of the patients were recorded as requiring "cot and chair" accommodation-that is, they were

TABle I.-Ages of Manchester Region Patients Awaiting Admission to Mental Deficiency Hospitals in December, 1958, by Grade and Sex

\begin{tabular}{|c|c|c|c|c|c|c|c|c|c|}
\hline \multirow{2}{*}{$\begin{array}{c}\text { Age- } \\
\text { group }\end{array}$} & \multicolumn{2}{|c|}{$\underset{\text { Grade }}{\text { High }}$} & \multicolumn{2}{|c|}{$\underset{\text { Grade }}{\text { Medium }}$} & \multicolumn{2}{|c|}{$\begin{array}{c}\text { Low } \\
\text { Grade }\end{array}$} & \multicolumn{2}{|c|}{ All } & \multirow{2}{*}{$\%$} \\
\hline & $\mathbf{M}$ & F & $\mathbf{M}$ & $\mathrm{F}$ & $\mathbf{M}$ & $\mathbf{F}$ & $\mathbf{M}$ & $\mathbf{F}$ & \\
\hline $\begin{array}{c}0-4 \\
5-9 \\
10-14 \\
15-19 \\
20-24 \\
25-34 \\
35-44 \\
45-54 \\
55-64 \\
65+ \\
\text { Not }\end{array}$ & $\begin{array}{l}0 \\
0 \\
0 \\
1 \\
8 \\
4 \\
5 \\
5 \\
7 \\
1\end{array}$ & $\begin{array}{r}0 \\
1 \\
2 \\
7 \\
2 \\
6 \\
7 \\
7 \\
10 \\
3\end{array}$ & $\begin{array}{r}6 \\
33 \\
51 \\
32 \\
12 \\
16 \\
15 \\
14 \\
8 \\
5\end{array}$ & $\begin{array}{r}4 \\
15 \\
17 \\
17 \\
15 \\
24 \\
16 \\
16 \\
9 \\
4\end{array}$ & $\begin{array}{r}24 \\
62 \\
41 \\
11 \\
8 \\
6 \\
5 \\
2 \\
4 \\
0\end{array}$ & $\begin{array}{r}20 \\
43 \\
17 \\
9 \\
4 \\
6 \\
7 \\
3 \\
0 \\
2\end{array}$ & $\begin{array}{r}30 \\
95 \\
92 \\
44 \\
28 \\
26 \\
25 \\
21 \\
19 \\
6\end{array}$ & $\begin{array}{r}24 \\
59 \\
36 \\
33 \\
21 \\
36 \\
30 \\
26 \\
19 \\
9\end{array}$ & $\begin{array}{r}7.9 \\
22.6 \\
18.8 \\
11.3 \\
7.2 \\
9.1 \\
8.1 \\
6.9 \\
5.6 \\
2.2\end{array}$ \\
\hline known & 0 & 2 & 1 & 0 & 0 & 0 & 1 & 2 & 0.4 \\
\hline tal & 31 & 47 & 193 & 137 & 163 & 111 & 387 & 295 & $\overline{100 \cdot 1}$ \\
\hline
\end{tabular}

